\title{
Guia de viagem para uma antropologia minimalista
}

Calavia Sáez, Oscar. Esse obscuro objeto da pesquisa - um manual de método, técnicas e teses em Antropologia. Ilha de Santa Catarina, Edição do Autor, 2013, 224 pp.

\author{
Rafael Rocha Pansica \\ Universidade de São Paulo
}

Que rumo dar aos manuais? Talvez seja este o mote desenvolvido por Oscar Calavia Sáez em Esse obscuro objeto da pesquisa - um manual de método, técnicas e teses em Antropologia. O livro que aqui se resenha oferece, com efeito, uma proposta de orientação que se afasta deliberadamente daqueles manuais redigidos como textos constitucionais da pesquisa para conceber-se, alternativamente, sob um formato afeito aos guias de viagens, i.e., a esses textos escritos por viajantes a partir de suas experiências de viagem para orientar aqueles interessados em empreender sua própria partida para alguma terra estrangeira. Mais bem inspirado na bússola que no leme, este manual etnográfico, em formato etnográfico de guia de viagem, busca orientar aqueles leitores desejosos por assumirem e autorarem suas próprias pesquisas.

Isto posto, vale observar que qualquer viajante, aspirante ou experiente, pode tirar proveito de um bom guia de viagem. $\mathrm{O}$ manual de pesquisa que aqui vamos introduzindo certamente constitui-se como um bom guia e interessará pesquisadores de todas as experiências etnográficas. $\mathrm{O}$ modo como o manual foi redigido oferece, com efeito, duas possibilidades de leitura: pode-se lê-lo como texto extenso ou como um conjunto articulado de verbetes sobre as diferentes etapas da pesquisa. Um leitor prestes a viajar para seu primeiro campo pode saltar os capítulos iniciais e aportar 
REVISTA DE ANTROPOLOGIA, SÃO PAULO, USP, $20 \mathrm{I}$, V. $58 \mathrm{~N}^{\mathrm{O}} \mathrm{I}$.

diretamente no capítulo sobre etnografia. Outro leitor, com dificuldades da elaboração do projeto, pode se valer imediatamente das orientaçôes sobre a construção do objeto no capítulo referente ao assunto. Este leitor, escritor desta resenha, decidiu pela leitura extensa - o que, além de se recomendar, é o que moldará a progressáo dos comentários que se seguem.

Introduzidas, organizadas e justificadas a partir de uma série de debates político-epistemológicos acerca da disciplina antropológica e da pesquisa etnográfica, as orientaçóes que Calavia Sáez oferece neste manual abarcam desde a vida universitária e a formação acadêmica, a elaboração do projeto e a execução da pesquisa etnográfica, até a redação do trabalho e a defesa da tese. As orientaçóes oferecidas pelo manual, portanto, se iniciam antes mesmo do início da pesquisa.

Ingressar na universidade já tem, por si, seus desdobramentos éticos. É bom que os universitários saibamos aproveitar os meios que a instituição nos oferece para que possamos realizar nossas pesquisas e formação acadêmicas sem, contudo, nos deixar atolar em sua densidade burocrática, seus hábitos institucionais ou seus modos elitizantes. Tão conservadora e reprodutora quanto outras instituições, as universidades propóem-se, ainda assim, como espaços adequados à crítica e à inovação - e se boa parte da crítica e da inovaçáo se dáo fora desse espaço, outra boa parcela se constitui intestinamente (sempre que se faz possível o desvencilhamento daqueles hábitos, modos e densidades referidos acima). Para aqueles que intentam cumprir a missão crítica e inovadora proposta pela universidade, agindo em conformidade com estes valores, é bom começar por reconhecer a tensão que o oficial ponto de vista institucional não reconhece entre seu discurso e sua prática - caso contrário, é provável que já se esteja, sem se saber, atolado na densidade conservadora e reprodutora da academia.

$\mathrm{Na}$ universidade, os estudantes recém-ingressados certamente se questionarão sobre os diferentes formatos dos cursos, das avaliaçóes e dos debates nas salas de aula. Neste movimento, reconhecerão logo a 
REVISTA DE ANTROPOLOGIA, SÃO PAULO, USP, $20 \mathrm{I}$, V. 58 N $\mathrm{N}^{\mathrm{O}} \mathrm{I}$.

importância dos xerox e/ou das listas de e-mails, dos dropboxes e das outras maneiras de acessar os textos eletrônicos das aulas. Poderão se deixar limitar nessas listas bibliográficas que lhe são oferecidas ou buscar se aventurar, por sua própria conta e risco, nas bibliotecas e nos mundos virtuais a procura de novos textos (antropológicos ou não): livros, artigos, teses, manuais, manifestos, obras de referência, etc. E talvez aí comecem a pensar, cada um, sobre seu papel em sua própria formação, estendendo os questionamentos dirigidos à tensão entre o discurso e a prática universitárias para se perguntar, a si mesmo, se seu discurso e prática andam coerentes ou apartados.

Com algum tempo na universidade, os alunos perceberão que podem aproveitar náo apenas de seu contexto de ensino, mas também de seus meios de pesquisa. Um outro universo da instituiçáo se abrirá a eles. Conhecerão a orientação; as agências de fomento e seus sistemas de avaliação; as dificuldades envolvidas na elaboração do projeto, na pesquisa etnográfica, na redação do trabalho e na defesa da tese. Nesta entrada, a escolha do orientador é de fundamental importância. A depender da escolha, poderá auxiliar mais a pesquisa do orientador, assumindo algumas de suas tarefas, do que ser auxiliado e orientado por ele na realizaçáo de sua própria pesquisa. $\mathrm{Ou}$, conforme suas intençôes, poderá privilegiar o lado empresarial de seu orientador, aproximando-se mais de seus conhecimentos sobre os critérios de avaliação das agências de fomento do que de sua expertise da temática, da bibliografia e do campo etnográfico. Como se pode perceber, trata-se sempre, de parte a parte, de questóes éticas referentes ao comportamento profissional.

Ao orientando iniciante caberá estudar seu tema de investigação: sua boa formação dependerá da leitura da bibliografia tutorada referente ao tema que deseja pesquisar. É somente a partir desses estudos orientados que o jovem pesquisador poderá construir seu objeto de pesquisa. Pois o objeto é menos aquilo que está dado no mundo, do que aquilo que se deve 
REVISTA DE ANTROPOLOGIA, SÃO PAULO, USP, $20 \mathrm{I}$, V. $58 \mathrm{~N}^{\mathrm{O}} \mathrm{I}$.

construir no plano mesmo do discurso antropológico como algo que merece melhor atençáo e/ou entendimento: trata-se, dito de outro modo, do refinamento e/ou da reconstrução de um fragmento mais ou menos bem estabelecido pela literatura acadêmica que, com astúcia e método, o pesquisador proporá modificar com sua pesquisa etnográfica. Tal construção deverá ser detalhadamente justificada (como viável, original e relevante) no projeto de pesquisa - texto que deve conter também um conjunto organizado das intençôes e das açôes planejadas para se realizar, em efetivo, a investigação. No manual que vamos resenhando, o leitor encontrará todas as orientaçóes sobre como escrevê-lo: desde dicas gramaticais sobre a construção do objeto, até consideraçóes sobre a natureza, o tamanho e a disposição das seçôes que devem compor o projeto (Introdução, Objeto, Justificativa, Objetivos, Método, Cronograma, Bibliografia).

Mas há mais: penso que o que há de mais interessante neste manual sobre a elaboração do projeto se encontra na série de consideraçóes acerca das particularidades que caracterizam a pesquisa etnográfica. Em um projeto de pesquisa etnográfica, a construção do objeto deveria ser, sempre segundo o manual, tão clara quanto justificada e, sobretudo, curta e provisória. Isso porque a etnografia, quando bem realizada, deveria poder modificar o objeto construído pelo projeto. No anti-laboratório que é o campo, são o objeto e o pesquisador as cobaias da pesquisa, pois são eles que sofrerão as transformaçóes motivadas pela experiência de deslocamento de um universo onde eles se encontram estabilizados (i.e., no projeto), para um universo empírico que lhes é estranho e, portanto, modificador. Morrer de amor pelo objeto construído no projeto não ajudará o pesquisador a exercer a abertura necessária para tais modificaçôes - abertura necessária que, por boas razóes, não é infinita: não apenas porque a habilidade pessoal do pesquisador em lidar com as transformaçôes da experiência etnográfica se mostrará sempre limitada (por mais ampla que seja), mas também porque o aprofundamento de 
REVISTA DE ANTROPOLOGIA, SÃO PAULO, USP, $20 \mathrm{I} 5$, V. $58 \mathrm{~N}^{\mathrm{O}} \mathrm{I}$.

sua experiência de campo inevitavelmente esbarrará nos limites éticos e expressivos do que não se pode, não deve ou não se consegue dizer.

Ademais, os desejos românticos do pesquisador iniciante de "virar nativo" - motivo de graça escarninha ou ofensa desrespeitosa para os pesquisados -, nem ao menos se justificam heuristicamente. Implicado nas relaçôes intersubjetivas que estabelece em campo, a única coisa que o pesquisador pode fazer é falar dessas relaçóes a partir de sua imersão nelas. Se o pesquisador não estuda exatamente o campo onde se insere, mas as modificações que sua inserção aí provoca, não haveria porque desejar tornar-se nativo. Ao contrário, deveria-se saber tirar proveito do potencial heurístico implicado na alteridade intersubjetiva que caracteriza a interação entre pesquisador e pesquisados.

Os tópicos que este manual traz sobre a arte e as técnicas da entrevista vão orientar os leitores, sempre a partir de consideraçóes a respeito dos imperativos éticos da interação etnográfica, sobre as maneiras de se bem aproveitar tal alteridade intersubjetiva: respeitar e inspirar-se no estilo de interlocuçáo do local; deixar o entrevistado falar evitando o reflexo de interrompê-lo quando, aparentemente, ele passa a falar de outra coisa (que relação essa outra coisa tem com o tema que lhe foi perguntado?); iniciar os encontros com conversas mais abertas para, gradualmente, passar a fazê-los sob roteiros mais estruturados, etc.

O leitor também encontrará orientaçôes acerca de outra arte/técnica imprescindível da pesquisa: o diário de campo. Esta escrita pessoal, reflexiva e heterogênea - entremeada de digressóes e interpretaçóes que, acrescentadas posteriormente sob o formato de notas laterais, vão se cruzando com as primeiras anotaçóes diárias - tem muita importância para o tipo de pesquisa que é a etnográfica. O diário de campo [1] suporta uma memória que, sem ela, pode se tornar mais lacunar e, ainda assim (ou por causa disso), mais linear e homogênea; [2] controla a quantidade massiva dos dados passíveis de serem coletados em campo a partir das novas tecnologias de 
REVISTA DE ANTROPOlOGIA, SÃo PAULO, USP, $20 \mathrm{I} 5$, V. $58 \mathrm{~N}^{\circ} \mathrm{I}$.

registro e armazenamento - as gravaçóes e as filmagens - construindo e sistematizando esses dados por meio da escrita; [3] comporta o que pode vir a ser o esquema narrativo da tese, se o pesquisador decidir escrever seu relato etnográfico a partir da sequência temporal do campo, mostrando como, quando e por quais caminhos o objeto de seu projeto de pesquisa foi se modificando na própria pesquisa de campo; etc. Feito para ser lido e relido muitas vezes, o diário de campo constitui-se também como exercício imprescindível de escrita (i.e., elaboração) etnográfica.

Náo por acaso, a escrita é um dos principais temas deste manual de pesquisa. Ela é alvo de desenvolvimento sistemático do autor nos mais diversos momentos do texto: das rápidas consideraçóes sobre a obra de Wittgenstein (que recebe uma leitura não ortodoxa) às proximidades sugeridas entre antropologia e literatura, passando pela linguagem comum como ferramenta descritiva, o relato como forma narrativa e a descrição etnográfica densa (mais adepta à de Evans-Pritchard que à de Geertz) como proposta de escrita teórica. De modo geral, o caráter sistemático das teorias costuma ser abstraído em uma formulaçáo conceitual sintética, isolada em uma posição de destaque na economia do texto, para ser tomada como a contribuição que a tese tem a dar aos debates acadêmicos. Tomada apenas como uma parte da tese, a teoria, assim compreendida, perderia o que Calavia Sáez considera ser sua grande contribuição, a saber, sua operacionalidade etnográfica. Informando a redação da tese, a teoria proposta pelo manual perde seu sentido de abstração conceitual para ganhar um sentido estritamente operacional, constituindo-se como algo que deve ganhar forma na descrição etnográfica. Tal proposta epistemológica é mais afeita à forma narrativa do relato, levada a cabo com as ferramentas da linguagem comum, do que ao formato narrativo monográfico, redigido com as ferramentas especializadas da linguagem conceitual: [1] se o clássico formato monográfico (aquele que estrutura o texto em capítulos como "vida econômica", 
REVISTA DE ANTROPOLOGIA, SÃO PAULO, USP, $20 \mathrm{I}$, V. 58 N $\mathrm{N}^{\mathrm{O}} \mathrm{I}$.

"organização social e parentesco", "cosmologia e mitologia”, etc.) organiza exteriormente o tecido contínuo da etnografia a partir da aplicação de um formato a priori, a forma relato (mais próxima às elaboraçóes do diário de campo) organiza-se através da etnografia, assumindo, caso a caso, formatos diversos conforme as particularidades de cada pesquisa; [2] se os conceitos da linguagem especializada valem por sua definição e abstração, os termos da linguagem comum valem por seu potencial tradutivo, i.e., por sua equivocidade e concretude: usados como signos à maneira dos bricoleurs intelectuais, os termos comuns são explorados nas suas virtualidades imprevistas: comunicam-se com mais facilidade entre os campos disciplinares (não apesar, mas a partir da exploração de sua equivocidade) e desfavorecem um uso mais autoritário e/ou elitista que, no debate acadêmico, um conceito pode vir a assumir.

Tais propostas sobre a escrita etnográfica - que interessarão, de um modo ou de outro, a toda sorte de pesquisadores (e que valem uma atenção mais demorada dos leitores) - constituem este manual também como um manifesto antropológico: um manifesto por uma "antropologia minimalista” (p. 207) que, infletindo os conceitos antropológicos no plano da linguagem comum, aposta em uma descrição etnográfica mais próxima das descriçôes levadas a cabo pela literatura (que não se utiliza de conceitos para constituir seu relato) e pela história (que, comparada ao projeto filosófico mais ortodoxo, tende, ao contrário, a operar num regime de formalização teórica menos abstrato). Mas há mais: esta antropologia pode se constituir como uma atividade política promissora: visto que o debate político tende a se realizar, apoiado no testemunho de cientistas mais positivistas, sobre o que costuma perceber como uma realidade única, quais efeitos uma ciência multinaturalista, feita com rigor e método (i.e, a antropologia como etnografia), poderia aí fazer surtir? O que míngua o debate público até sua insignificância, afirma o autor, é a falácia dessa realidade única que a antropologia, ciência 
REVISTA DE ANTROPOLOGIA, SÃO PAULO, USP, $20 \mathrm{I}$, V. $58 \mathrm{~N}^{\mathrm{O}} \mathrm{I}$.

etnográfica dos possíveis humanos, tem todas as condiçôes de desmontar: "Os antropólogos-etnógrafos têm acesso a dados que revelam outras realidades, não apenas no passado ou nesse mundo marginal dos Outros, mas bem no aqui e agora. E, por estarem atentos à diferença, podem detectar melhor os objetos que surgem a cada momento, modificando a teia da realidade em que jogam" (p. 208). A ambição desse projeto antropológico, que se assume como ciência etnográfica, é a de descobrir, no dinamismo perpétuo da rede social-empírica (feita das interaçôes entre agentes, pacientes, discursos, teorias e outros nós), a emergência de novos objetos etnográficos.

Não poderia finalizar esta resenha sem destacar alguns pontos referentes aos aspectos formais do texto (que, como vimos, assumem grande importância para seu autor). Querendo escapar das mais variadas burocracias institucionais envolvidas nas tarefas de publicação de um livro (edição, impressão, publicização, distribuição, etc), Calavia Sáez decidiu lançá-lo independentemente, divulgando-o gratuitamente na internet sob o formato mais ecologicamente responsável do texto eletrônico. O manual pode ser acessado, por exemplo, em < www.antropologia. com.br/divu/colab/d53-osaez.pdf >. Ainda que algumas imagens merecessem um pouco mais de cuidado na sua resolução gráfica e a redação do texto deslize, aqui e ali, em palabras escritas em espanhol (o autor é espanhol...), a edição independente do autor se redige sob preocupaçóes estéticas afeitas à sua proposta de mútua implicação entre forma e conteúdo textuais: se os inícios dos capítulos são marcados por uma pequena imagem que funciona, na economia do texto, como epígrafe - o que me parece ser um uso criativo dos recursos imagéticos (vale a pena, a esse respeito, conferir os comentários que o autor tece acerca das ambiçóes narrativas de uma certa linha da antropologia visual); os finais dos capítulos são marcados pelo que o autor intitula como Notas Bibliográficas, i.e., consideraçóes sucintas, registradas numa fonte distinta daquela 
REVISTA DE ANTROPOLOGIA, SÃO PAULO, USP, $20 \mathrm{I} 5$, V. 58 No I.

escolhida para o resto do texto, que funcionam menos como referências bibliográficas que como caminhos para o debate acadêmico - tratam-se de sugestóes de textos e de autores cujas posiçóes, em geral, são contrárias às defendidas no manual. A redação dessas Notas Bibliográficas vem apontar também a importância que, para o autor, assumem os debates acadêmicos (i.e., científicos e políticos): mais uma razão forte para a divulgação gratuita do livro na rede pública. Por fim, a possibilidade de ler o livro como texto extenso ou como um conjunto articulado de verbetes não se apresentaria caso a teoria e a ética que o informam não se espraiassem, fractalmente, pelo texto todo. 